\title{
The Motivation of Arab EFL University Students towards Using Mall Applications for Speaking Improvement
}

\author{
Abdullah A. Almadhady ${ }^{1, *}$, Abdul Rahim Haji Salam², Harmi Izzuan Baharum ${ }^{3}$ \\ ${ }^{1}$ Faculty of Social Science \& Humanities, Universiti Teknologi Malaysia (UTM), Skudai, Johor, Malaysia \\ ${ }^{2}$ Language Academy, Universiti Teknologi Malaysia (UTM), Skudai, Johor, Malaysia \\ ${ }^{3}$ Language Academy, Universiti Teknologi Malaysia Kuala Lumpur (UTM Kuala Lumpur), Kuala Lumpur, Malaysia
}

Received June 24, 2020; Revised September 12, 2020; Accepted November 7, 2020

\begin{abstract}
Cite This Paper in the following Citation Styles
(a): [1] Abdullah A. Almadhady, Abdul Rahim Haji Salam, Harmi Izzuan Baharum, "The Motivation of Arab EFL University Students towards Using Mall Applications for Speaking Improvement," Universal Journal of Educational Research, Vol. 8, No. 11C, pp. 23 - 36, 2020. DOI: 10.13189/ujer.2020.082304.
\end{abstract}

(b): Abdullah A. Almadhady, Abdul Rahim Haji Salam, Harmi Izzuan Baharum (2020). The Motivation of Arab EFL University Students towards Using Mall Applications for Speaking Improvement. Universal Journal of Educational Research, 8(11C), 23 - 36. DOI: 10.13189/ujer.2020.082304.

Copyright $\bigcirc 2020$ by authors, all rights reserved. Authors agree that this article remains permanently open access under the terms of the Creative Commons Attribution License 4.0 International License

\begin{abstract}
MALL could be applied to improve English speaking of EFL students. One of the important issues related to the use of MALL applications is the motivation towards using these applications by learners. The main aim of this study is to identify the motivation of using MALL applications by Arab EFL students for English speaking improvements. A conceptual model was proposed based on Technology Acceptance Model (TAM). The proposed model presents seven research hypotheses to test the relationship among three layers of variables. The independent variables include the external reasons to use MALL applications such as accessibility, availability, and variety of learning styles. The motivational factors of using MALL applications (mediating variables) include such as usefulness and ease of use. The third model layer is the actual use of MALL applications (dependent variables) such as the attitudes toward using MALL applications. A questionnaire survey was conducted with 152 students at Al-Anbar University in Iraq. The data analyzed using SEM through AMOS tool. The results showed that the students are motivated to use MALL application for speaking improvements due to the ease of use and the usefulness of these applications. The students' motivation is supported by many reasons such as MALL accessibility, availability, enjoyment, variety of learning styles, and flexibility in learning.
\end{abstract}

Keywords MALL (Mobile Assisted Language
Learning), English Speaking, Motivation, Arab EFL Students, TAM

\section{Introduction}

Improving the speaking skills of EFL learners is in the core focus of many studies. It has been proven by researchers that the success in language learning is measured by the ability to speak the language and to carry out a conversation "(Gou, 2013; Leong \& Ahmadi, 2017; Sheppard, 2004). Therefore, speaking could be considered of a high priority to EFL learners (Florez, 1999) as it has the potential to increase the overall learners' motivation and to help making the language learning as a fun and dynamic experience (Nunan, 1999: cited in Fauzan, 2016 \& Celce-Murcia, 2001). Furthermore, speaking can also promote other language skills (Farabi et al. 2017)."

Many previous studies have shown that Arab EFL learners are encountering serious problems in speaking $(\mathrm{Al}$ Hosni, 2016; Al-Jamal \& Ghadeer, 2014; Al Nakhalah, 2016). Al Hosni (2014) argued that speaking skills of Arab EFL students should be improved effectively due to its direct implementation in oral communication. However, the speaking skills of Arab EFL learners are still below the expectations of what? (Alrabai, 2016; Alrashidi \& Phan, 
2015; Fareh, 2010). Pathan, Aldersi, \& Alsout (2014) and Lukitasari (2003) concluded that that Arab EFL students are de-motivated to learn the mastering of speaking skills due to difficulty of learning the English speaking (i.e. the mother tongue interference difficulty). Al-Jamal \& Miqdadi (2013) concluded that at an EFL setting, speaking disability refers to problems such as mother tongue communication, big classes, and shortage of class time.

Ramamuruthy (2019) believes that there is a strong relationship between speaking skills and language anxiety. His study has proven that there is undeniable impact of speaking skills on the language anxiety of students which lead to a low language proficiency. The more anxious the learners became, the lower grades they achieved. On the other hand, some other studies have shown the readiness of students to use the web-based speaking skills resources as a way to improve the speaking skills (Fuad, N. I. M., Shah, P. M., \& Mohamad, M., 2019). Among the instruments of the study the motivation and the technology accessibility were used as in this research.

The above mentioned challenges of speaking learning raises the importance of Arab EFL students' motivation to allocate more time and efforts to improve their speaking skills through practicing communication activities. This justifies the importance of motivating the self-directed learning activities outside the classrooms (Hadriana et al., 2013; Thanh Pham \& Renshaw, 2015). Marzuki et al (2016) conducted a study on improving EFL learners' speaking ability. The findings revealed that self-directed learning strategy has a big impact on improving the learners' motivation to speak which in a certain way will lead to improve the EFL learners' speaking competence.

The advent of mobile technologies in applications assisting language learning process seems to be generally accepted and growing. "The wide use of smartphones and other portable devices have been significantly changing the ways of learning in many contexts, including language learning (Kukulska-Hulme, 2009). MALL is a key aspect of language learning and it is regarded as one of the most pertinent application areas. As far as MALL is concerned, many studies have investigated the impact of using smart phones on language learning and language skills improvement (Alemi, 2012; Al-Jarf, 2012 (Cited in Jenny, Nasser, and Reddy 2016); Chinnery, 2006; Demouy, V., Eardley, A., Shrestha, P., \& Kukulska-Hulme, 2011; Hui Guo, 2013; Kim \& Kwon, 2013). In most of the studies the participants expressed their satisfactions and they have shown their motivations towards using current mobile apps for English language learning, and for improving certain language skills."

In summary, the studies have proven that mobile applications have encouraged exciting opportunities for personal and autonomous learning environments with flexibility and reliability of access to learning materials anytime and anywhere. The innovative and interesting ways of learning have a potential to increase the learners' motivation and to encourage permanent learning habits. Based on the above, the current study is aiming to identify the motivation of using the MALL applications to enhance the speaking skills among Arab EFL university students.

\section{Theoretical Considerations}

There are many theories supporting the standpoint of this research (improving the English speaking skills of EFL students using MALL environment). VARK theory was developed by Fleming in 1987, is one of the important related theories which describes four modalities of student learning. VARK stands for (Visual, Aural, Read/Write, and Kinesthetic learning styles). Based on VARK, the effective learning activities would be conducted based on the combination of two or more learning styles, and these styles are visual, aural, read/write, and kinesthetic (Brown et al., 2008). The visual style includes the learning events such as images, posters, videos, and diagrams. The aural style includes the learning events such as audio, music, discussion, and guest speakers. The read/write style includes events such as instructions, handbooks, and handouts. The kinesthetic style includes events such as drama, moving around, and artifacts. Therefore, the learning activities based on various learning styles and events could be effective to enhance the English speaking learning performance of EFL students according to their preferred styles.

Technology Acceptance Model (TAM) is another theory which suggests the measuring aspects of acceptance the use of technology facilities (infrastructures and services) (Davis, 1985). In 1985, Fred Davis develops TAM to measure the users' technology acceptance (Davis, 1985). The main factor of TAM is the user motivation, which consists of two variables; the technology usefulness and the ease of use. Davis measured the technology acceptance by analyzing the motivation of using systems features and capabilities and evaluated the measurement through the actual use of the systems. Figure 1 illustrates Davis' proposed model."

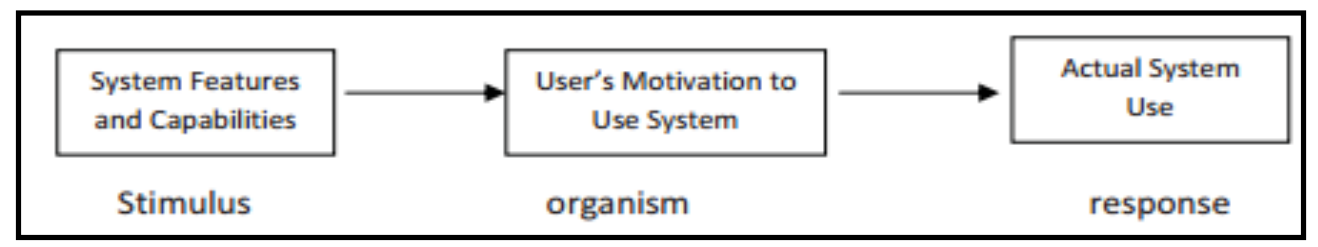

Figure 1. Aspects of Technology Acceptance Theory (Davis, 1985) 


\section{Method}

The study collected a quantitative data using a questionnaire survey due to usability of the questionnaire in collecting data from large number of respondents in short time and less efforts. The purpose of the data collection is to explore the motivation of using MALL applications by Arab EFL students. The questionnaire items were adapted from various resources (Aqda et al., 2011; Chau \& Hu, 2002; Davis, 1989; Henesey, 1991; Ku et al., 2009; Slyke et al., 2007; Vlachos \& Vrechopoulos, 2008). Furthermore, many of the questionnaire items were adapted from models such as TAM and VARK. However, some of the questionnaire items were developed to fulfill the need of the study objective. Thus, the initiated questionnaire was reviewed by five experts in the English speaking domain, and the given comments are updated in order to finalize the final questionnaire draft.

Arab EFL university students represent the main area of this research. AL-Anbar University in Iraq is the scope of the research study. The population of this research is EFL students in the English department in the Faculty of Education for Humanities at Al-Anbar University. According to the formal site of this university, the population of English department is composed of 384 undergraduate students. A population is defined as "a collection of individuals or objects that form the main focus of a scientific enquiry" (Castillo, 2009), while the study sample is the targeted respondents from the population.

According to Yount (2006), the percentage of study sample should be $10 \%$ at minimum for the size of population between 101-1000 respondents. The population of this study is 384 undergraduate EFL students. Hence, the minimum sample number that should be collected is about 40 students. However, the researcher will try to collect at minimum 150 questionnaire responses from the study population in order to meet effective research requirements.

The sampling method adopted in this study is the non-probability sampling, which is also referred to as the quota sampling. This type of sampling was chosen owing to confidentiality policies in the universities, which prevented the researcher from obtaining data about the students due to privacy issues. Convenience sampling is suitable to draw samples from convenient sampling units (readily available).

As for the sampling technique, the sample selection was conducted depending on the sample segment's usefulness and was based on a distinct proportion. The study questionnaire used a sampling technique namely quota sampling. The justification behind using the quota sampling method is due to the fair of data collection from EFL students (Heeringa, 2004). Based on the quota technique, the collected sample in this research will be from different academic years of undergraduate EFL students; first, second, third, and fourth academic years. It is expected to collect about $35-40$ responses from EFL students in each academic year.

\subsection{Measurement}

Table 1 presents the measurement variables of the questionnaire in this study. The total of the constructed measurement items is 28 distributed on three sub-models (i.e. second order factors). The first sub-model is the external factors, which are represented by five first order dimensions; availability of MALL applications (3 items), accessibility of MALL applications (2 items), flexibility of MALL features (3 items), Variety of learning styles using MALL applications (4 items), and enjoyment of using MALL applications in learning processes (4 items). This sub-model represents the independent factor in the measure construction.

The second measurement construction is the motivational model, which is the second order that contains two main variables of first order; usefulness of using MALL applications (4 items), and ease of use of the MALL applications (4 items). This sub-model represents the mediating factor in the measurement construction.

The third measurement construction is the actual use model, which is the second order that contains one variable of first order that is the attitudes toward using MALL applications in improving the English speaking skills (4 items). This sub-model represents the dependent factor in the measurement construction.

Table 1. Orders of measurement variables and items

\begin{tabular}{|c|c|c|}
\hline $\begin{array}{l}\text { Second } \\
\text { order }\end{array}$ & First order & $\begin{array}{c}\text { Number of } \\
\text { Items }\end{array}$ \\
\hline \multirow{5}{*}{$\begin{array}{l}\text { External } \\
\text { factors }\end{array}$} & Availability of MALL resources. & 3 \\
\hline & $\begin{array}{l}\text { Accessibility of MALL } \\
\text { resources. }\end{array}$ & 2 \\
\hline & Flexibility of MALL features. & 3 \\
\hline & Variety of learning styles & 4 \\
\hline & $\begin{array}{c}\text { Enjoyment of using MALL } \\
\text { applications. }\end{array}$ & 4 \\
\hline \multirow{2}{*}{$\begin{array}{l}\text { Motivational } \\
\text { factors }\end{array}$} & $\begin{array}{c}\text { Usefulness of MALL } \\
\text { applications }\end{array}$ & 4 \\
\hline & Ease of use MALL applications. & 4 \\
\hline $\begin{array}{l}\text { Actual use } \\
\text { factors }\end{array}$ & $\begin{array}{l}\text { Attitudes toward using MALL } \\
\text { applications to improve speaking }\end{array}$ & 4 \\
\hline Total & & 28 \\
\hline
\end{tabular}

\subsection{Analysis Method}

In this study, Structured Equation Modeling (SEM) using AMOS software was conducted to test the overall hypotheses due to the mediating structure of the theoretical model. SEM is a very general and very powerful multivariate analysis technique. SEM is often used to assess unobservable 'latent' constructs. The links between constructs of a structural equation model may be estimated with independent regression equations or through more involved approaches. In specifying pathways in a model, the modeler can posit two types of relationships: (1) free 
pathways, in which hypothesized causal (in fact counterfactual) relationships between variables are tested, and therefore are left 'free' to vary, and (2) relationships between variables that already have an estimated relationship, usually based on previous studies, which are 'fixed' in the model. SEM includes confirmatory factor analysis, path analysis, partial least squares path analysis, LISREL and latent growth modeling. Thus, SEM will be effective to test the developed hypotheses in this research (Bennett, 2004).

\section{Results Discussion}

This section presents the discussion of the study results including the demographic analysis, confirmatory Factor Analysis (CFA), descriptive Analysis, and the Structural Equation Model (SEM).

\subsection{Response Rate and Demographic Data}

The questionnaire data was collected from Iraqi EFL students in the English department faculty of Education of Al-Anbar University. The questionnaire was distributed to 200 EFL students. Out of 200 distributed questionnaires, 37 questionnaires were not returned and 11 questionnaires were not used due to incomplete answers. Thus, 152 questionnaires were considered as valid for data analysis purpose. The response rate of the collected data was $76 \%$, and it indicated a good responses rate. This indicates the effective time that offered the students to complete the questionnaire and the students' awareness of the study importance to enhance the learning activities of the English speaking.

Depending on the valid 152 collected responses, the respondents' demographic data were analyzed to assure their validity in providing useful data to support the questionnaire study. The demographic analysis is to confirm the usefulness of the collected data. The respondents should match with the targeted characteristics of the study scope such as gender, ages, and academic year in the university. On the other hand, the respondents should have the experiences in using mobile applications for learning purposes in order to be able to understand the questionnaire items.

The questionnaire includes seven demographic variables that are: (1) gender, (2) age, (3) university academic level, (4) challenges in improving the speaking skills, (5) possession of mobile devices, (6) experience in using the mobile applications, and (7) purpose of using the mobile applications. Table 2 summarizes the demographic analysis of the 152 respondents in this study.

In the above Table, the percentages reflect the balance between male and female students in providing their opinions about the motivation of using MALL applications to improve the speaking skills. The respondents' ages represent the realistic ages of university students, which is usually between 18-24 years. Moreover, the analysis of academic year variable confirms the researcher applying of quota technique in selecting the questionnaire respondents. From each academic year of the university study (first, second, third, and fourth) 38 students provide their responses. Furthermore, the analysis of the speaking challenges variable confirms the importance of this study in utilizing MALL applications to enhance the speaking skills of English language by university EFL students. Additionally, the analysis of fifth demographic variable indicates the familiarity of the respondents with using supporting facilities of MALL applications, which allow the respondents to provide useful data to support this study. Also, the sixth demographic variable reflects the good experience of the respondents in using the mobile applications. Thus, they are able to provide data about the use of MALL application based on their understanding of the features of mobile applications. Lastly, the seventh demographic variable shows the respondents' awareness in using the mobile applications for purposes such as learning activities. The provided data from the respondents would be useful to determine their motivation in utilizing MALL applications in their learning activities to improve their English speaking skills. 
Table 2. Analysis of Demographic Data

\begin{tabular}{|c|c|c|c|}
\hline Variable & Items & Frequency & Percentage \\
\hline \multirow{2}{*}{ Gender } & Male & 65 & $43 \%$ \\
\hline & Female & 87 & $57 \%$ \\
\hline \multirow{5}{*}{ Age } & $<21$ years & 34 & $22 \%$ \\
\hline & $21-25$ years & 107 & $70 \%$ \\
\hline & $26-30$ years & 7 & $5 \%$ \\
\hline & $31-35$ years & 4 & $3 \%$ \\
\hline & $>35$ years & 0 & $0 \%$ \\
\hline \multirow{4}{*}{ University academic year } & First year & 38 & $25 \%$ \\
\hline & Second year & 38 & $25 \%$ \\
\hline & Third year & 38 & $25 \%$ \\
\hline & Fourth year & 38 & $25 \%$ \\
\hline \multirow{4}{*}{$\begin{array}{l}\text { Having challenges in improving your } \\
\text { English speaking skills? }\end{array}$} & Yes & 119 & $78 \%$ \\
\hline & Yes, but not critical & 16 & $11 \%$ \\
\hline & No & 5 & $3 \%$ \\
\hline & No, but I need more effective learning processes & 12 & $8 \%$ \\
\hline \multirow{6}{*}{ How many mobile devices do you own? } & 0 & 0 & $0 \%$ \\
\hline & 1 & 95 & $62 \%$ \\
\hline & 2 & 41 & $27 \%$ \\
\hline & 3 & 10 & $7 \%$ \\
\hline & 4 & 0 & $0 \%$ \\
\hline & More than 4 & 6 & $4 \%$ \\
\hline \multirow{5}{*}{$\begin{array}{l}\text { How long have you been using the mobile } \\
\text { applications? }\end{array}$} & Never & 0 & $0 \%$ \\
\hline & Months & 0 & $0 \%$ \\
\hline & Months & 9 & $6 \%$ \\
\hline & $1-2$ years & 39 & $26 \%$ \\
\hline & Above 2 years & 104 & $68 \%$ \\
\hline \multirow{6}{*}{$\begin{array}{l}\text { For what purpose do you use your mobile } \\
\text { device? }\end{array}$} & Phone calls & 0 & $0 \%$ \\
\hline & Messaging and Phone calls & 0 & $0 \%$ \\
\hline & Gaming & 0 & $0 \%$ \\
\hline & Social Network Communication & 5 & $3 \%$ \\
\hline & Learning services & 50 & $33 \%$ \\
\hline & All services & 97 & $64 \%$ \\
\hline
\end{tabular}




\subsection{Data Screening and Data Normality}

The data screening processes aim to confirm that the respondents completed their responses effectively. For this purpose, the responses of missing values should be excluded from the data analysis. On the other hand, the outlier data or responses should be removed. The outlier data is the responses that does not match with the total scale of the responses. This section explains the missing values and data outliers' tests.

The first data screening process is the removing of the missing values. The collected 152 responses were entered carefully to SPSS to perform the data screening tests. According to Tabachnick and Fidel (2007) the acceptance missing values is 0.05 for each first order variable in the questionnaire. The first order variables of missing values more than 0.05 should be excluded from the data analysis. Based on this percentage, there is no need to exclude any responses from the collected 152 questionnaires. The research assures that the used 152 responses are completely responding to all of the questionnaire items that distributed on eight first order variables. All 152 respondents have answered about all items in the questionnaire, and there are no blank answers are founded in this test.

The second data screening process is removing the outliers. Hair et al., (1998) argued that the responses that are not adding meaning to the variables should be removed in order to assure useful data analysis. In other word, the outlier responses are the data that are not matching with the normal distribution of the total collected data. One of the most known outliers' tests is the univariaste (Hair et al., 1998; Tabachnick and Fidell 2007). The outliers' tests were applied on the 152 acceptable responses based on the missing values processes. The univariate outlier test was conducted based on Z-score technique using SPSS tool, whereby the Z-score should be in the boundary between -4 to 4 (Hair et al., 1998; Tabachnick and Fidell 2007). The $Z$-score test on the 152 responses in this study shows that all responses to the 28 items are acceptable (in the range between -4 to 4 ).

The data normality is another conducted analysis to confirm the data validity. The data normality aims to estimate the normal distribution of the questionnaire responses. The normal distribution of the data indicates the good relationship between the item responses in order to support the validity of the study variables. By using AMOS, two normality assessments were conducted; (1) Skewness, whereby the average of the data normal distribution should fall in the range -3 to 3 ; and the Kurtosis, whereby the average of the data normal distribution must fall in the range -7 to 7 . Both Skewness and Kurtosis tests were accomplished using AMOS tool. The two normality tests confirm that all item responses belong to the normal distribution of the applied tests. Hence, the collected data are interrelated to support the modeling of the study variables, which allow the next analysis steps such as CFA.

\subsection{Confirmatory Factor Analysis and Descriptive Analysis}

According to Hair et al., (2006), the data CFA test focuses on the measurement of data scales based on the model construction. The collected data must be integrated accurately with the study factors that comprise the proposed model. The weak representation of the study factors through the collected data may lead to a failure in model construction.

One of the known accuracy tests of the data scales is the Confirmatory Factor Analysis (CFA), which considers as the first stage of the SEM analyses (Hair et al., 2006). CFA aims to measure several accuracy directions such as the fitness of the model factors, the factors reliability, and the relationships within/among the study factors. This section presents the CFA analysis for the three main study factors; external factors of MALL applications (such as availability and enjoyment), motivation of MALL applications (ease of use and usefulness), and the actual use of MALL applications (attitudes). The CFA conducted using AMOS tool due to the effectiveness of AMOS to perform the several accuracy tests of CFA.

The CFA model is performed based on 28 items distributed on eight main variables of first order construction; There are many CFA analyses conducted to assure the reliability and validity of the model data such as the factor loading, goodness of fit indices, reliability and convergent validity, and discriminant validity.

Based on all 28 items that are included in the overall CFA model analysis, the validity test (factor loading test) is applied to determine the correspondence level between the items in each factor. The validity test aims to assure the interrelation between the items of the model dimensions. The validity could indicate if there are strong connections between the responses to represent the model dimensions. According to Nunnally and Bernstein (1994), the acceptance level of the factor loading (validity) should be more than 0.5.

Based on the factor loading -in Appendix A- there are 5 items should be removed from the model due to unacceptable loading i.e. less than 0.5 (FL3, VLS1, EJ2, EJ4, UF2). The factors loading of the entire 23 items are acceptable to include in the next step of CFA analysis. The MALL accessibility factor is represented by 2 items (AC1 and AC2), the MALL availability factor is represented by 3 items (AV1-AV3), the MALL flexibility factor is represented by 2 items (FL1 and FL2), the variety of learning styles represented by 3 items (VLS2-VLS4), and MALL enjoyment contains 2 items (EJ1 and EJ3). On the other hand, the Ease of use factor stills is represented by 4 items (EOU1-EOU4), and the MALL usefulness is represented by 3 items (UF1, UF3, and UF4). Furthermore, the attitude toward using MALL applications is represented by four items (AT1- AT4).

Based on the entire 23 items in the modified model, the 
reliability and convergent validity tests were conducted. The reliability coefficients (Cronbach alpha) are 0.92 for the accessibility dimension, 0.851 for the availability dimension, 0.743 for the flexibility dimension, 0.922 for the variety of learning styles, 0.816 for the enjoyment dimension, 0.937 for the ease of use, 0.74 for the usefulness, and 0.813 for the attitudes dimension. Hence, the reliability is acceptable for all included dimensions in the modified model. Furthermore, the composite reliability of each dimension is strong $(>0.7)$ based on the related path with other dimensions. In conclusion, the reliability of the modified model is very good and indicates the careful data filled by the respondents. On the other hand, the convergent validity based on AVE test shows that all dimensions are above the acceptable cut point of the valid relationships between the dimensions $(>0.5)$. This indicates the good interrelation between the items of all dimensions.

Hair et al. (1995) mentioned that the in-acceptable fit coefficient of the indices requires the retest of the correlation paths between the model items to improve the model fit through reducing the indirect or hidden relationship between the items (i.e. to enhance the $x^{2}$ value). The first sub-model includes the independent or external factors of using MALL applications; accessibility, availability, flexibility, variety of learning styles, and enjoyment. Based on the recommended tests values, the model records acceptable corresponding among all 12 items that represent this sub-model.

The results of goodness of fit indices confirm the good interrelationships among the data of all 12 items that belong to first-sub model. The GFI coefficient is 0.927 , whereby the acceptable cut value of the GFI should be more than 0.8 (Hoyle, 1995). The cut value of the Adjusted GFI (AGFI) records 0.914, and regarding to Chau and $\mathrm{Hu}$ (2001) this cut value is acceptable fit indicator (i.e. $>0.8$ ). On the other hand, the acceptable value of the CFI, TLI, and IFI indices should be more than 0.9 (Bagozzi \& Yi., 1988; Hair et al., 2006). All of these test record acceptable fit values, the CFI coefficient 0.925 , the TLI coefficient is 0.941 , and the IFI coefficient is 0.937 . Furthermore, the RMSEA is one of the most important tests to assure the fitness of the model, and the coefficient of RMSEA must be below 0.1 (Schumacker \& Lomax, 2010). The RMSEA test records 0.03 , which is acceptable coefficient that indicates the fitness among the model items. The results of all conducted tests are matched with the adequacy of $X^{2} / \mathrm{df}$ (3.32), which is below the cut value of 5 . In summary, the modified CFA for the first sub- model is fit. Hence, the model data would be adopted for further SEM analysis such as research hypotheses tests.

In order to test the relationship between the model factors, the discriminant validity is conducted on the overall model. The discriminant validity test is important to assure the interrelation between the dimensions of the modified model. The discriminant validity is different of the correlation test; it estimates the relationship between the dimensions and the square root of the average variance that extracted for each dimension (Fornell \& Larcker, 1981). Kline (2005) mentioned that the accepted discriminant correlations among the dimensions should be below 0.85 , and the discriminant correlations among the items in the same dimension should be near to 1 . Table 3 presents the discriminant validity of the first sub-model.

Table 3. Discriminant Validity of the First Sub-model

\begin{tabular}{|c|c|c|c|c|c|}
\hline & $\mathbf{A C}$ & $\mathbf{A V}$ & $\mathbf{F L}$ & $\mathbf{V L S}$ & EJ \\
\hline $\mathbf{A C}$ & $\mathbf{0 . 8 8 1}$ & & & & \\
\hline $\mathbf{A V}$ & $0.841^{* * *}$ & $\mathbf{0 . 9 0 5}$ & & & \\
\hline $\mathbf{F L}$ & $0.751^{* * *}$ & $0.818^{* * *}$ & $\mathbf{0 . 8 9 8}$ & & \\
\hline $\mathbf{V L S}$ & $0.676^{* * *}$ & $0.755^{* * *}$ & $0.791^{* * *}$ & $\mathbf{0 . 9 2 1}$ & \\
\hline $\mathbf{E J}$ & $0.581^{* * *}$ & $0.684^{* * *}$ & $0.562^{* * *}$ & $0.622^{* * *}$ & $\mathbf{0 . 8 7 3}$ \\
\hline
\end{tabular}

Based on the above Table 3, it can be noticed that the inter-correlations are valid in/among all dimensions in the modified model, which indicates strong interrelation level between the model factors. The inter-correlation is less than the $r^{2}$ of the average variance extracted from each dimension $(0.881,0.905,0.898,0.921$, and 0.873 respectively for accessibility, availability, flexibility, variety of learning styles, and enjoyment), whereby the discriminant validity of the modified sub-model is confirmed. In conclusion, the CFA of the first sub- model (goodness of fit, reliability and convergent validity, and discriminant validity) confirms the construction usefulness of model. On the other hand, the CFA tests are conducted for the second sub-model in this study, which includes the mediating or motivational factors of using MALL applications; ease of use and usefulness. Based on the recommended tests values, the model records acceptable corresponding among all 7 items that represent this sub-model.

The results of goodness of fit indices confirm the good interrelationships among the data of all 7 items that belong to second-sub model. The GFI coefficient is 0.85 , the AGFI records 0.834 , the CFI coefficient is 0.911 , the TLI coefficient is 0.920 , and the IFI coefficient 0.935 . The RMSEA test records 0.045 , which is acceptable coefficient that indicates the fitness among the model items. The results of all conducted tests are matched with the adequacy of $X^{2} / \mathrm{df}(3.05)$, which is below the cut value of 5 . In summary, the modified CFA for the second sub- model is fit. Hence, the model data would be adopted for further SEM analysis such as research hypotheses tests.

Table 4 presents the discriminant validity of the first sub-model. The inter-correlations are valid in/among all dimensions in the modified model, which indicates strong interrelation level between the model factors. The inter-correlation is less than the $r^{2}$ of the average variance extracted from each dimension $(0.901$ and 0.917 respectively for ease of use and usefulness, whereby the 
discriminant validity of the modified sub-model is confirmed.

Table 4. Discriminant Validity of the second Sub-model

\begin{tabular}{|c|c|c|}
\hline & EoU & UF \\
\hline EoU & $\mathbf{0 . 9 0 1}$ & \\
\hline UF & $0.822 * * *$ & $\mathbf{0 . 9 1 7}$ \\
\hline
\end{tabular}

In conclusion, the CFA of the second sub- model (goodness of fit, reliability and convergent validity, and discriminant validity) confirms the construction usefulness of model.

The third sub-model in this study is the actual use of MALL applications to improve the speaking skills and this model represented by only one factor (attitudes). Thus, the CFA for this sub-model is not needed. The CFA is important when the sub-model includes two factors or more.

The above CFA tests confirm the fitness of the sub-models in this study in order to assure the effective relationships among the variables and items within the factors (i.e. external factor or motivational factor). In section 4.6 the SEM tests are conducted based on the 23 items that represent the overall model in this research.

Based on the modified model, the descriptive analysis is conducted using 23 items that are distributed on eight main variables that are related to the uses of MALL applications to improve the English speaking skills; accessibility, availability, flexibility, variety of learning styles, enjoyment, usefulness, ease of use, and attitudes. The main aim of the descriptive analysis is to analyze the directions of the respondents' motivation of using MALL application in their learning activities. The items were analyzed based on the 5-likert scale; 1 for Strongly Disagree (SD), 2 for Disagree (D), 3 for Neutral (N), 4 for Agree (A), and 5 for Strongly Agree (SA).

Table 5 summarizes the descriptive analysis of the responses about the accessibility of MALL application in speaking. In this study, MALL accessibility belongs to the independent (external) factors, which represent the characteristics of MALL applications for speaking. In total, the respondents see that MALL applications allow them to perform their learning processes in any palace and based on self-directed learning.

Table 6 shows the descriptive analysis of the availability of MALL applications resources to improve the speaking skills. This variable is independent and represents one of the main characteristics of MALL applications. The respondents are strongly agreeing with AV1 and AV2 items and Agreeing with AV2 item. Therefore, the respondents understand the availability characteristic of MALL application in the activities of speaking learning.

Table 5. Descriptive Analysis of MALL Accessibility

\begin{tabular}{|c|c|c|c|c|c|c|c|c|}
\hline Item\# & Item & SD & D & N & A & SA & Mean & $\begin{array}{c}\text { Agreement } \\
\text { Level }\end{array}$ \\
\hline AC1 & I can use the mobile applications in any place. & 0 & 0 & 0 & 41 & 111 & 4.73 & Strongly Agree \\
\hline AC2 & $\begin{array}{c}\text { Using mobile applications allow me to do } \\
\text { self-directed learning for English speaking. }\end{array}$ & 0 & 0 & 0 & 76 & 76 & 4.50 & Strongly Agree \\
\hline
\end{tabular}

Table 6. Descriptive Analysis of MALL Availability

\begin{tabular}{|c|c|c|c|c|c|c|c|c|}
\hline Item\# & Item & SD & D & N & A & SA & Mean & Agreement Level \\
\hline AV1 & Mobile applications are available at any time. & 0 & 0 & 1 & 48 & 103 & 4.67 & Strongly Agree \\
\hline AV2 & $\begin{array}{c}\text { Mobile applications provide real-time and updated } \\
\text { information about English learning I am willing to use }\end{array}$ & 0 & 0 & 1 & 80 & 71 & 4.46 & Agree \\
\hline AV3 & $\begin{array}{c}\text { The available mobile application help me to improve my } \\
\text { speaking skills informally (without teacher support) }\end{array}$ & 0 & 0 & 0 & 51 & 101 & 4.66 & Strongly Agree \\
\hline
\end{tabular}


Table 7 presents the descriptive analysis of the flexibility of MALL applications to improve the speaking skills. MALL flexibility is one of the main factors that are considered as independent variables in this study. The respondents are strongly agreeing with FL1 item and Agreeing with FL2 item. Hence, the respondents could be motivated to use MALL applications due to flexible features of these applications in performing the learning activities.

Table 8 shows the descriptive analysis of the variety of learning styles of MALL applications. MALL applications would present the speaking improving based on various learning styles such as videos, audio, images, and texts. In this study, the variety of learning styles is considered as independent variable. The respondents are strongly agreeing with all items in this variable (VLS2, VLS3, and VLS4). In total, the respondents would be motivated to use MALL applications in their speaking activities due to the variety of learning styles, whereby every student can improve his/her speaking skills based on customized and preferred learning style(s).

Table 9 shows the descriptive analysis of the enjoyment of MALL applications to improve the speaking skills. This variable is independent and represents one of the main characteristics of MALL applications. The respondents are strongly agreeing with EJ1 item and agreeing with EJ3 item. Therefore, the enjoyment of using MALL applications may motivate the students to use these applications to improve their speaking skills.

The Tables 5-9 show the descriptive analysis of the independent or external variables in this study. In summary, the respondents believe that MALL applications offer many characteristics to improve the speaking skills. MALL applications allow the students to perform their learning activities form anyplace and in anytime (accessibility and availability). MALL applications would provide flexible functionality to perform the learning activities in effective ways (flexibility). Moreover, MALL applications offer the learning materials based on various learning styles (i.e. variety of learning styles), whereby the students can customize the prefer learning style(s) in their learning processes. Additionally, the students see that using MALL applications is enjoyable and fun to improve their speaking skills.

Table 7. Descriptive Analysis of MALL Flexibility

\begin{tabular}{|c|c|c|c|c|c|c|c|c|}
\hline Item\# & Item & SD & D & N & A & SA & Mean & Agreement Level \\
\hline FL1 & $\begin{array}{c}\text { The mobile applications can be used effectively } \\
\text { to enhance my English speaking skills. }\end{array}$ & 0 & 0 & 0 & 63 & 89 & 4.58 & Strongly Agree \\
\hline FL2 & $\begin{array}{c}\text { Mobile applications offer a good variety ways to } \\
\text { improve my English speaking. }\end{array}$ & 0 & 0 & 10 & 65 & 77 & 4.44 & Agree \\
\hline
\end{tabular}

Table 8. Descriptive Analysis of Varity Learning Styles of MALL

\begin{tabular}{|c|c|c|c|c|c|c|c|c|}
\hline Item & Item\# & SD & D & N & A & SA & Mean & Agreement Level \\
\hline VLS2 & $\begin{array}{c}\text { I prefer to improve my English speaking skills } \\
\text { based on mixed learning styles. }\end{array}$ & 0 & 1 & 3 & 50 & 98 & 4.61 & Strongly Agree \\
\hline VLS3 & $\begin{array}{c}\text { Mobile applications offer the learning style(s) that } \\
\text { I prefer to improve my English speaking skills }\end{array}$ & 0 & 1 & 3 & 62 & 86 & 4.53 & Strongly Agree \\
\hline VLS4 & $\begin{array}{c}\text { The various learning styles that offered by mobile } \\
\text { application help me to improve my speaking skills } \\
\text { outside the classroom. }\end{array}$ & 0 & 0 & 2 & 59 & 91 & 4.58 & Strongly Agree \\
\hline
\end{tabular}

Table 9. Descriptive Analysis of MALL Enjoyment

\begin{tabular}{|c|c|c|c|c|c|c|c|c|}
\hline Item\# & Item & SD & D & N & A & SA & Mean & Agreement Level \\
\hline EJ1 & $\begin{array}{c}\text { Using the mobile applications is enjoyable to improve my } \\
\text { English speaking skills. }\end{array}$ & 0 & 0 & 0 & 71 & 81 & 4.53 & Strongly Agree \\
\hline $\mathbf{E J 3}$ & $\begin{array}{c}\text { It is Fun to improve my English speaking skills through the } \\
\text { use of various mobile applications and facilities. }\end{array}$ & 0 & 2 & 6 & 65 & 79 & 4.45 & Agree \\
\hline
\end{tabular}


In terms of the motivational factors (mediating variables) of using MALL application, the descriptive analysis is conducted for 2 variables; MALL ease of use and MALL usefulness. Table 10 presents the descriptive analysis of the ease of use of MALL applications. The respondents are strongly agreeing with EOU2 and EOU4 items and agreeing with EOU1 and EOU 3 items. This analysis indicates the students' motivation to use MALL applications for improving the speaking skills due to the ease of use of these applications. The students haven't concerns toward the difficulty of using MALL applications to improve their speaking skills.

Table 11 presents the descriptive analysis of usefulness of using MALL applications to improve the speaking skills. The respondents are agreeing with all items in this variable. In total, the students believe that using MALL applications would be useful to improve the speaking skills. Thus, the students could be motivated to use MALL applications for speaking improvement.

In terms of the actual use (dependent factor) of MALL applications to improve the speaking skills, the descriptive analysis is conducted for the attitudes toward using MALL applications by EFL students (Table 12). The respondents are agreeing with items AT1 and AT2 and strongly agreeing with items AT3 and AT4. n total, the respondents have positive attitudes toward the actual use of MALL application to improve English speaking skills.

In conclusion, the descriptive analysis of the questionnaire reflects the opinions of the university EFL students about the use of MALL applications to improve the speaking skills. The respondents see that MALL applications have many characteristics to support the learning activities. The respondents are motivated to benefit from MALL characteristics due to other motivational factors such as the ease of use and usefulness of MALL applications. Thus, the respondents provide positive attitudes toward the actual use of MALL in order to improve their English speaking learning. The next section discusses the structural equation model and the hypotheses testing.

Table 10. Descriptive Analysis of MALL Ease of Use

\begin{tabular}{|c|r|c|c|c|c|c|c|c|}
\hline Item\# & Item & SD & D & N & A & SA & Mean & $\begin{array}{c}\text { Agreement } \\
\text { Level }\end{array}$ \\
\hline EOU1 & $\begin{array}{c}\text { It is easy to operate the mobile applications for } \\
\text { learning purposes. }\end{array}$ & 0 & 0 & 9 & 64 & 79 & 4.46 & Agree \\
\hline EOU2 & $\begin{array}{c}\text { I think it easy to get the mobile applications to } \\
\text { do what I want to do. }\end{array}$ & 0 & 0 & 2 & 64 & 86 & 4.55 & Strongly Agree \\
\hline EOU3 & $\begin{array}{c}\text { The mobile applications are flexible to interact } \\
\text { with. }\end{array}$ & 0 & 0 & 10 & 59 & 83 & 4.48 & Agree \\
\hline EOU4 & $\begin{array}{c}\text { It is easy for me to improve my speaking skills } \\
\text { using mobile applications. }\end{array}$ & 0 & 1 & 5 & 47 & 99 & 4.60 & Strongly Agree \\
\hline
\end{tabular}

Table 11. Descriptive Analysis of MALL Usefulness

\begin{tabular}{|c|c|c|c|c|c|c|c|c|}
\hline Item\# & Item & SD & D & N & A & SA & Mean & Agreement Level \\
\hline UF1 & $\begin{array}{c}\text { Using mobile applications give me greater } \\
\text { control over my learning processes. }\end{array}$ & 0 & 0 & 15 & 82 & 55 & 4.26 & Agree \\
\hline UF3 & $\begin{array}{c}\text { Using mobile applications increase my } \\
\text { learning productivity. }\end{array}$ & & 5 & 72 & & 75 & 4.46 & Agree \\
\hline UF4 & $\begin{array}{c}\text { Using mobile applications enhances my } \\
\text { learning activity. }\end{array}$ & 0 & 0 & 1 & 79 & 72 & 4.47 & Agree \\
\hline
\end{tabular}

Table 12. Descriptive Analysis of Attitudes toward using MALL

\begin{tabular}{|c|c|c|c|c|c|c|c|c|}
\hline Item\# & Item & SD & D & N & A & SA & Mean & Agreement Level \\
\hline AT1 & $\begin{array}{c}\text { I am willing to use mobile applications in the future (i.e. } \\
\text { next year) to improve my English speaking skills. }\end{array}$ & 0 & 0 & 5 & 81 & 66 & 4.40 & Agree \\
\hline AT2 & $\begin{array}{c}\text { I am willing to use the mobile applications soon to improve } \\
\text { my English speaking skills. }\end{array}$ & 0 & 0 & 6 & 70 & 76 & 4.46 & Agree \\
\hline AT3 & $\begin{array}{c}\text { I will try to use more kinds of mobile applications to } \\
\text { improve my English speaking skills. }\end{array}$ & 0 & 0 & 5 & 64 & 83 & 4.51 & Strongly Agree \\
\hline AT4 & $\begin{array}{c}\text { I will strongly recommend others to use mobile applications } \\
\text { to improve their English speaking skills. }\end{array}$ & 0 & 0 & 0 & 65 & 87 & 4.57 & Strongly Agree \\
\hline
\end{tabular}


Table 13. Direct Paths Test

\begin{tabular}{|c|c|c|c|c|c|c|c|}
\hline \multirow{2}{*}{ Path } & \multicolumn{2}{|c|}{ Unstandardized Estimate } & \multirow{2}{*}{$\begin{array}{c}\begin{array}{c}\text { Standardized } \\
\text { Estimate }\end{array} \\
\text { Beta } \\
\end{array}$} & \multirow{2}{*}{ c.r. } & \multirow{2}{*}{ P-value } & \multirow{2}{*}{$\begin{array}{c}\text { Sub } \\
\text { Hypotheses Results }\end{array}$} & \multirow{2}{*}{$\begin{array}{c}\text { Overall } \\
\text { Hypotheses results }\end{array}$} \\
\hline & Estimate & S.E. & & & & & \\
\hline $\mathrm{AC} \rightarrow \mathrm{EoU}$ & 0.247 & 0.092 & $0.26^{* *}$ & 2.215 & 0.005 & H1a: Supported & \multirow{2}{*}{ H1: Supported } \\
\hline $\mathrm{AC} \rightarrow \mathrm{UF}$ & 0.234 & 0.081 & $0.24^{* *}$ & 2.113 & 0.005 & H1b: Supported & \\
\hline $\mathrm{AV} \rightarrow \mathrm{EoU}$ & 0.231 & 0.081 & $0.41^{* *}$ & 2.326 & 0.009 & H2a: Supported & \multirow{2}{*}{ H2: Supported } \\
\hline $\mathrm{AV} \rightarrow \mathrm{UF}$ & 0.252 & 0.065 & $0.30^{* *}$ & 2.876 & 0.008 & H2b: Supported & \\
\hline $\mathrm{FL} \rightarrow \mathrm{EoU}$ & 0.226 & 0.079 & $0.35^{* *}$ & 2.861 & 0.005 & H3a: Supported & \multirow{2}{*}{ H3: Supported } \\
\hline $\mathrm{FL} \rightarrow \mathrm{UF}$ & 0.098 & 0.051 & $0.19^{*}$ & 2.553 & 0.013 & H3b: Supported & \\
\hline $\mathrm{VLS} \rightarrow \mathrm{EoU}$ & 0.133 & 0.049 & $0.18^{*}$ & 2.534 & 0.016 & H4a: Supported & \multirow{2}{*}{ H4: Supported } \\
\hline $\mathrm{VLS} \rightarrow \mathrm{UF}$ & 0.112 & 0.045 & $0.21^{* *}$ & 2.811 & 0.008 & H4b: Supported & \\
\hline $\mathrm{EJ} \rightarrow \mathrm{EoU}$ & 0.145 & 0.091 & $0.17^{*}$ & 2.122 & 0.019 & H5a: Supported & \multirow{2}{*}{ H5: Supported } \\
\hline $\mathrm{EJ} \rightarrow \mathrm{UF}$ & 0.207 & 0.086 & $0.31^{* *}$ & 2.854 & 0.006 & H5b: Supported & \\
\hline EoU $\rightarrow$ AT & 0.172 & 0.059 & $0.19^{*}$ & 2.416 & 0.014 & H6a: Supported & \multirow{2}{*}{ H6: Supported } \\
\hline $\mathrm{UF} \rightarrow \mathrm{AT}$ & 0.135 & 0.042 & $0.23^{* *}$ & 2.919 & 0.007 & H6b: Supported & \\
\hline
\end{tabular}

\subsection{Structural Equation Model (SEM)}

The SEM is conducted based on 8 variables of 23 items; accessibility of 2 items, availability of 3 items, flexibility of 2 items, variety of learning styles of 3 items, and enjoyment of 2 items; 4 items for ease of use, usefulness of 3 items, and attitudes of 4 items. Figure 2 illustrates the SEM of overall model in this study. The next two sub sections present the testing of six direct effect hypotheses and the one mediating hypotheses.

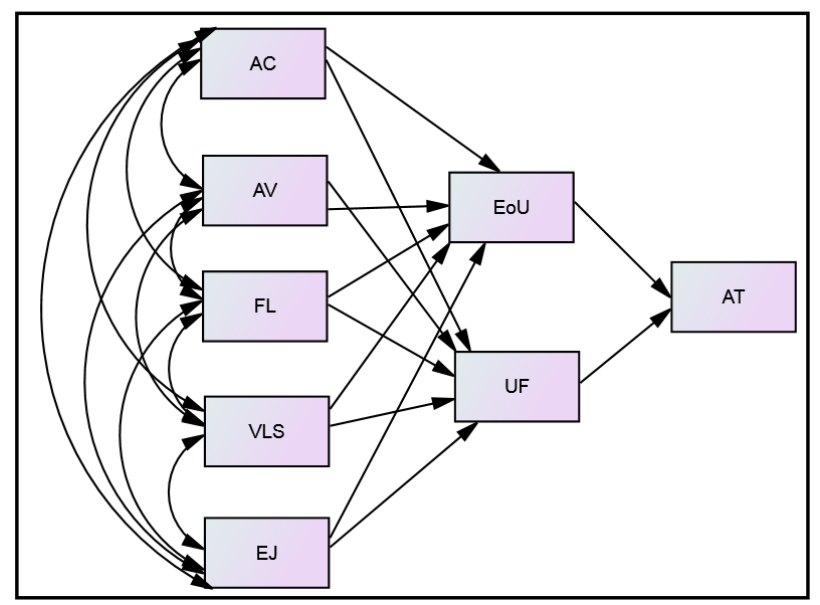

Figure 2. Structural Equation Model

\subsubsection{Direct Effect Hypotheses}

This study is directional relationship using a significance level p-value of 0.05 to test the effect for the possibility of the relationship in one/direct direction. The relationship of P-value that $<=0.05$ represents the supporting of the research hypotheses, while the P-value that $>0.05$ represents the rejection of the research hypotheses. Table 13 summarizes the direct paths test among all factors in this study.

Based on the above Table 14, the six direct research hypotheses can be judged based on the P-value. The direct research Hypotheses are as the following:

H1) there is a positive relationship between the accessibility of MALL applications and the motivation of English speaking improvement (ease of use and usefulness): In terms of relationship between MALL accessibility (AC) and the ease of use (EoU), the C.R. and p-value are 2.215 and 0.005 respectively. It indicates that the probability of getting C.R. as large as 2.215 in absolute value is 0.005 . Furthermore, the relationship between the $\mathrm{AC}$ and usefulness (UF), the C.R. is 2.113 and the p-value is significant at 0.005 . Thus hypothesis $\mathrm{H} 1$ is supported due to significant relationship between the $\mathrm{AC}$ and motivational factors of MALL applications (EoU and UF) . This means that the accessibility of MALL resources plays an important role in motivating the use of MALL applications to improve speaking skills.

H2) there is a positive relationship between the availability of MALL applications and the motivation of English speaking improvement (ease of use and usefulness): In terms of relationship between MALL availability (AV) and the ease of use (EoU), the C.R. and p-value are 2.326 and 0.009 respectively. Also, the relationship between the AV and usefulness (UF) records C.R. as 2.876 and the p-value is significant at 0.008 . Therefore, hypothesis $\mathrm{H} 2$ is supported. The availability of MALL resources plays an important role in motivating the use of MALL applications to improve the speaking skills.

H3) there is a positive relationship between the flexibility of MALL applications and the motivation of English speaking improvement (ease of use and usefulness): The C.R. is 2.861 and the P-value is 0.005 for the relationship between MALL flexibility (FL) and the ease of use (EoU). On the other hand, The C.R. is 2.553 and the P-value is 0.013 for the relationship between MALL flexibility (FL) and usefulness (UF). Hence, hypothesis H3 is supported. This indicates that the flexibility of MALL applications plays an important role in motivating the use of MALL applications to improve the speaking skills. 
H4) there is a positive relationship between the learning styles of MALL applications and the motivation of English speaking improvement (ease of use and usefulness): The C.R. is 2.534 and the P-value is 0.016 for the relationship between the learning styles of MALL (VLS) and the ease of use (EoU). On the other hand, The C.R. is 2.811 and the P-value is 0.008 for the relationship between the VLS and usefulness (UF). Hence, hypothesis H4 is supported. This indicates that the variety of learning styles of MALL applications plays an important role in motivating the use of MALL applications to improve the speaking skills.

H5) there is a positive relationship between the enjoyment of MALL applications and the motivation of English speaking improvement (ease of use and usefulness): In terms of the relationship between MALL enjoyment (EJ) and the ease of use (EoU), the C.R. and p-value are 2.122 and 0.019 respectively. Also, the relationship between the EJ and usefulness (UF) records C.R. as 2.854 and the p-value is significant at 0.006 . Therefore, hypothesis H5 is supported. The enjoyment in using MALL applications plays an important role in motivating the use of MALL applications to improve the speaking skills.

H6) there is a positive relationship between the motivation of using MALL applications (ease of use and usefulness) and the actual use of MALL applications (attitudes) to improve English speaking skills: The C.R. is 2.416 and the $\mathrm{P}$-value is 0.014 for the relationship between the ease of use (EoU) and the attitudes (AT). On the other hand, The C.R. is 2.919 and the P-value is 0.007 for the relationship between the usefulness (UF) and AT. Hence, hypothesis H6 is supported. This indicates that the motivational factors of MALL applications are significant to encourage the students' attitudes toward using MALL applications to improve the speaking skills.

In conclusion, all directed hypotheses in this research are supported, whereby the EFL students are motivated for the actual use of MALL applications to improve their speaking skills. The high motivation level is due to various characteristics of MALL applications such as accessibility, availability, flexibility, variety of learning styles, and enjoyment. To confirm this conclusion, the next sub section discusses the indirect (mediating) research hypothesis (H7).

\subsubsection{Mediating Effect Hypotheses}

According to Browne et al., (1993) and Garver and Mentzer (1999), SEM approach is preferable to regression techniques for testing mediation effect. This is because SEM technique allows modeling of both measurement and structural relationship and generates overall fir indices. This study used bootstrapping approach as recommended by Bagozzi and Yi (1988) to test the research hypothesis \#7. Table 14 summarizes the paths analysis of the mediating effects between the study variables, which reflect the test of research hypothesis \#7. The paths analysis shows that all mediating paths are significant $(\mathrm{P}$-value $<0.05)$. This represents the strong supporting of $\mathrm{H} \# 7$.

Table 14. Paths test for research hypothesis \#7

\begin{tabular}{|c|c|c|}
\hline Specific Indirect effect & Standardized total effect & P-value \\
\hline AC-> EoU-> AT & .188 & $.004^{* *}$ \\
\hline AC-> UF-> AT & 0.131 & $.008^{* *}$ \\
\hline AV-> EoU-> AT & .124 & $.009^{* *}$ \\
\hline AV-> UF-> AT & .167 & $.019^{*}$ \\
\hline FL-> EoU-> AT & .192 & $.005^{* *}$ \\
\hline FL-> UF-> AT & .152 & $.016^{*}$ \\
\hline VLS-> EoU-> AT & .181 & $.006^{* *}$ \\
\hline VLS-> UF-> AT & .179 & $.005^{* *}$ \\
\hline EJ-> EoU-> AT & .146 & $.016^{*}$ \\
\hline EJ-> UF-> AT & .190 & $.007^{* *}$ \\
\hline
\end{tabular}

Based on the above Table 14, all indirect paths in the study model records significant relationship among the study variables. For examples, there is a significant relationship at $\mathrm{P}$-value $<0.05$ in terms of the relationship between MALL accessibility (AC) and Attitudes toward using MALL (AT) through MALL usefulness (UF). This means that the hypotheses \#7 is strongly supported.

\section{Conclusion}

In total, the testing of the research hypotheses addresses the first research objective, which is to determine the motivation behind using MALL applications among Arab EFL university students for speaking improvement. The results of the collected questionnaire data show that EFL students have positive attitudes toward the use of MALL applications to improve the English speaking skills. The positive attitudes are due to the motivational factors such as ease of use and usefulness of MALL applications. The students are motivated to use MALL applications because they believe that theses application are easy to be used and useful to improve the speaking skills based on self-directed learning. In addition, there are many external factors motivating EFL students to use MALL applications such as the accessibility and availability of MALL resources, flexibility of MALL applications in performing the speaking activities, variety of learning styles to deliver the learning materials using MALL applications, and the enjoyment of using MALL applications by EFL students. In the future, a specific MALL application(s) will be applied in speaking learning in order to determine the impact of MALL applications in improving the speaking skills of the EFL university students. The motivation of using MALL reflects the students' attitudes toward the actual use of MALL applications in the future. The contribution of this study is the exploring of various variables that could motivate the use of MALL applications by EFL students for speaking improvements. This indicates the importance of the effective use of MALL applications to improve the speaking skills of EFL students in the Arab world universities. 


\section{Appendix A: Factor Loading}

\begin{tabular}{|c|c|c|c|}
\hline Items Label & Construct name & $\begin{array}{c}\text { Estimate } \\
\text { Loading }\end{array}$ & Item reference code \\
\hline T1 & Accessibility & 0.710 & $\mathrm{AC} 1$ \\
\hline $\mathbf{T 2}$ & Accessibility & 0.712 & $\mathrm{AC} 2$ \\
\hline T3 & Availability & 0.52 & AV1 \\
\hline T4 & Availability & 0.61 & AV2 \\
\hline T5 & Availability & 0.679 & AV3 \\
\hline T6 & Flexibility & 0.772 & FL1 \\
\hline T7 & Flexibility & 0.649 & FL2 \\
\hline T8 & Flexibility & 0.021 & FL3 \\
\hline T9 & Variety of learning styles & -0.16 & VLS1 \\
\hline T10 & Variety of learning styles & 0.809 & VLS2 \\
\hline T11 & Variety of learning styles & 0.628 & VLS3 \\
\hline T12 & Variety of learning styles & 0.731 & VLS4 \\
\hline T13 & Enjoyment & 0.560 & EJ1 \\
\hline T14 & Enjoyment & -0.363 & $\mathrm{EJ} 2$ \\
\hline T15 & Enjoyment & 0.812 & EJ3 \\
\hline T16 & Enjoyment & -0.313 & EJ4 \\
\hline T17 & Ease of Use & 0.882 & EOU1 \\
\hline T18 & Ease of Use & 0.813 & EOU2 \\
\hline T19 & Ease of Use & 0.860 & EOU3 \\
\hline T20 & Ease of Use & 0.503 & EOU4 \\
\hline $\mathbf{T} 21$ & Usefulness & 0.902 & UF1 \\
\hline T22 & Usefulness & 0.247 & UF2 \\
\hline $\mathbf{T} 23$ & Usefulness & 0.60 & UF3 \\
\hline $\mathrm{T} 24$ & Usefulness & 0.628 & UF4 \\
\hline T25 & Attitudes & 0.690 & AT1 \\
\hline T26 & Attitudes & 0.541 & AT2 \\
\hline T27 & Attitudes & 0.553 & AT3 \\
\hline $\mathrm{T} 28$ & Attitudes & 0.567 & AT4 \\
\hline
\end{tabular}

\section{REFERENCES}

[1] Al Hosni, S. (2014). Speaking difficulties encountered by young EFL learners. International Journal on Studies in English Language and Literature (IJSELL), 2(6), 22-30. www.arcjournals.org

[2] Al Nakhalah, A. M. (2016). Problems and Difficulties of Speaking That Encounter English Language Students at Al Quds Open University. International Journal of Humanities and Social Science Invention ISSN. Volume 5 Issue 12/ PP.96-101

[3] Al-Jamal, Dina A., and Ghadeer A. Al-Jamal. (2013). An investigation of the difficulties faced by EFL undergraduates in speaking skills. English Language Teaching, 7(1), 19.

[4] Alrabai, F. (2016). Factors underlying low achievement of
Saudi EFL learners. International Journal of English Linguistics, 6(3), 21.

[5] Alrashidi, O., \& Phan, H. (2015). Education context and English teaching and learning in the Kingdom of Saudi Arabia: An overview. English Language Teaching, 8(5), 33.

[6] Aqda, M. F., F. Hamidi \& F. Ghorbandordinejad 2011. The impact of constructivist and cognitive distance instructional design on the learner's creativity. Procedia computer science 3: 260-265.

[7] Azli, W. Shah, P. M., \& Mohamad, M. (2018). Perception on the Usage of Mobile Assisted Language Learning (MALL) in English as a Second Language (ESL) Learning among Vocational College Students. Creative Education, 9(01), 84.

[8] Brown, T., Cosgriff, T., \& French, G. (2008). Learning style preferences of occupational therapy, physiotherapy and speech pathology students: a comparative study. Internet Journal of Allied Health Sciences and Practice, 6(3), 7. 
[9] Bennett, A. (2004). Case study methods: Design, use, and comparative advantages. Models, numbers, and cases: Methods for studying international relations, 19-55.

[10] Chau, P. Y., \& Hu, P. J. H. (2001). Information technology acceptance by individual professionals: A model comparison approach. Decision sciences, 32(4), 699-719.

[11] Farabi, M., Hassanvand, S., \& Gorjian, B. (2017). Using Guided Oral Presentation in Teaching English Language Learners' Speaking Skills. Journal of Applied Linguistics and Language Learning, 3(1), 17-24.

[12] Fareh, S. (2010). Challenges of teaching English in the Arab world: Why can't EFL programs deliver as expected? Procedia-Social and Behavioral Sciences, 2(2), 3600-3604.

[13] Fauzan, U. (2016). Enhancing speaking ability of EFL Students through debate and peer assessment. EFL journal, 1(1), 49-57.vol. 1 no. 1 www.efljournal.org

[14] Florez, M. A. C. (1999). Improving Adult English Language Learners' SpeakingSkills.

[15] Fuad, N. I. M., Shah, P. M., \& Mohamad, M. (2019). ESL Pupils' Acceptance towards Web-based Speaking Skills Resource: Sub-urban and Rural Context. Universal Journal of Educational Research, 7(10A), 60-65.

[16] Garver, M. S., \& Mentzer, J. T. (1999). Logistics research methods: employing structural equation modeling to test for construct validity. Journal of business logistics, 20(1), 33.

[17] Guo, H. (2013). Analyzing and Evaluating Current Mobile Applications for Learning English Speaking. University of London. Recuperado de.

[18] Hadriana, H., Ismail, M. A., \& Mahdum, M. (2013). The relationship between motivations and self-learning and the English language achievement in secondary high school students. Asian Social Science, 9(12), 36.

[19] Hair, J. F. (1995). ua (1995): Multivariate Data Analysis with Readings. Englewood Cliffs.

[20] Heeringa, S. G., Wagner, J., Torres, M., Duan, N., Adams, T., \& Berglund, P. (2004). Sample designs and sampling methods for the Collaborative Psychiatric Epidemiology Studies (CPES). International journal of methods in psychiatric research, 13(4), 221-240.

[21] Hwang, W. Y. et. al. (2014). Improving English as a foreign language writing in elementary schools using mobile devices in familiar situational contexts. Computer Assisted Language Learning, 27(5), 359-378.

[22] Kabilan, M. K., Ahmad, N., \& Abidin, M. J. Z. (2010). Facebook: An online environment for learning of English in institutions of higher education?. The Internet and higher education, 13(4), 179-187.

[23] Kim, C., Mirusmonov, M., Lee, I. (2010). An empirical examination of factors influencing the intention to use mobile payment. Computers in Human Behavior, 26(3), $310-322$

[24] Kim, H., \& Kwon, Y. (2012). Exploring smartphone applications for effective mobile-assisted language learning.
Multimedia-Assisted Language Learning, 15(1), 31-57.

[25] Kline, R. B. (2005). Methodology in the social sciences.

[26] Kukulska-Hulme, A. (2009). Will mobile learning change language learning? ReCALL, 21(2), 157-165. European Association for Computer Assisted Language Learning.

[27] Kukulska-Hulme, A., Pettit, J., Bradley, L., Carvalho, A. A., Herrington, A., Kennedy, D. M., \& Walker, A. (2011). Mature students using mobile devices in life and learning. International Journal of Mobile and Blended Learning (IJMBL), 3(1), 18-52.

[28] Leong, L. M., \& Ahmadi, S. M. (2017). An analysis of factors influencing learners' English speaking skill. International Journal of Research in English Education, 2(1), 34-41.

[29] Lukitasari, N. (2003). Students' Strategies in Overcoming Speaking Problems in Speaking Class. University of Muhammadiyah Malang.

[30] MacCallum, R. C., \& Browne, M. W. (1993). The use of causal indicators in covariance structure models: Some practical issues. Psychological bulletin, 114(3), 533.

[31] Marzuki, M., Prayogo, J. A., \& Wahyudi, A. (2016). Improving the EFL learners' speaking ability through interactive storytelling. Dinamika Ilmu, 16(1), 15-34..

[32] Meldrum, K. (2010). Structural equation modelling: tips for getting started with your research.

[33] Miqdadi, R., \& Al-Jamal, D. (2013). Difficulties in Content and Language Integrated Learning: The Case of Math. Jordan Journal of Educational Science, 9(4), 449-459.

[34] Orme, J. G., \& Combs-Orme, T. (2009). Multiple regression with discrete dependent variables. Oxford University Press.

[35] Pathan, M., Aldersi, Z., \& Alsout, E. (2014). Speaking in their language: An overview of major difficulties faced by the Libyan EFL learners in speaking skill. International Journal of English Language \& Translation Studies, 2(3), 96-105.

[36] Ramamuruthy, V. (2019). The Effects of Task-based Approach on Speaking Anxiety among ESL Low Proficiency Diploma Students. Universal Journal of Educational Research, 7(6), 1363-1375.

[37] Shahrokhi, M., \& Kamyabi, M. (2016). The Impact of Mobile Assisted Language Learning (MALL) on Phrasal Verbs of Iranian Intermediate EFL Students. In Handbook of Research on Mobile Learning in Contemporary Classrooms (pp. 217-239). IGI Global.

[38] Slyke, C.V., Ilie, V., Lou, H., Stafford, T. (2007). Perceived critical mass and the adoption of a communication technology. European Journal of Information Systems, 16(3), 270-283.

[39] Xu, Q., \& Peng, H. (2017). Investigating mobile-assisted oral feedback in teaching Chinese as a second language. Computer Assisted Language Learning, 30(3-4), 173-182.

[40] Yount, W. R. (2006). Research design and statistical analysis for Christian ministry. 